\title{
Immunogenicity of various Vibrio ordalii lipopolysaccharide fractions in coho salmon Oncorhynchus kisutch
}

\author{
M. I. Velji ${ }^{1}$, L. J. Albright ${ }^{1}$, T. P. T. Evelyn ${ }^{2}$ \\ ${ }^{1}$ Department of Biological Sciences, Simon Fraser University, Burnaby, British Columbia, Canada V5A 1S6 \\ ${ }^{2}$ Department of Fisheries and Oceans, Biological Sciences Branch, Pacific Biological Station, Nanaimo, British Columbia, \\ Canada V9R 5K6
}

\begin{abstract}
The immunogenicity of intraperitoneally injected native Vibrio ordalii (Vo) lipopolysaccharide (LPS) and of various Vo LPS fractions obtained by preparative sodium dodecyl sulphate polyacrylamide gel electrophoresis (SDS-PAGE) was examined in coho salmon Oncorhynchus kisutch. Immunogenicity was assessed using a challenge with live Vo cells, the challenge being sufficient to kill. 85 to $87 \%$ of the control fish not receiving any Vo preparations. Native Vo LPS afforded the strongest protection, the relative percentage survival (RPS) being $85.3 \%$. LPS fractions were found to contain 2 or more LPS components, and protective immunity associated with the fractions appeared to decline (from 51.4 to $5.9 \%$ RPS) as the molecular weight of the slowest migrating components in the fractions decreased. In fact, only those fractions containing LPS with molecular weights of $20 \mathrm{kD}$ or above resulted in significant protection. We conclude that the higher molecular weight species of Vo LPS were the ones that were largely responsible for the anti-Vo immunity induced in coho by native LPS, and, based on the ladderlike pattern produced by the LPS on SDS-PAGE, we think it likely that the different LPS species represented molecules differing from one another largely in the number of O-polysaccharide repeat units present. Aggregation of the LPS molecules also occurred, and the possibility that aggregation may have contributed to the immunogenicity of the protective LPS fractions cannot be ruled out.
\end{abstract}

\section{INTRODUCTION}

Salmonids vaccinated with killed whole cells, cell wall extracts, or extracellular products of the fish pathogenic vibrios Vibrio anguillarum (Va) and Vibrio ordalii (Vo) have been shown to be protected from vibriosis caused by these organisms (Evelyn 1984). Using polyclonal antisera and immunoblotting, Chart \& Trust (1984) showed that the major surface antigen of these vibrios was lipopolysaccharide (LPS), and the evidence is now convincing that LPS is, in fact, the protective antigen produced by each of these species (Evelyn 1988, Velji et al. 1990).

As judged by sodium dodecyl sulphate polacrylamide gel electrophoresis (SDS-PAGE), LPS produced by $V o$ appears to be considerably more heterogeneous than that produced by certain of the Va serotypes (Chart \& Trust 1984). However, based on the ladderlike pattern of Vo LPS bands observed, and by analogy with the findings of others for such LPS banding patterns (Goldman \& Lieve 1980, Palva \& Makela 1980), it is likely that the heterogeneity in Vo LPS is largely accounted for by the differing number of repeat units present in the various $\mathrm{O}$-polysaccharide chains.

We have shown that LPS extracted from Vo cells or released to the culture medium by Vo during growth is immunogenic in extremely small quantities. The immunogenicity, measured in terms of anti-vibrio protection in juvenile coho salmon Oncorhynchus kisutch, was demonstrated in fish that had been vaccinated by either of 2 routes: by immersion or by injection (Velji et al. 1990)

The purpose of the present study was to determine whether all of the different molecular weight species of Vo LPS contribute to the protective immunity observed with native Vo LPS. We therefore fractionated Vo LPS by preparative SDS-PAGE (P-PAGE) and tested the resulting LPS fractions for their protectiveness in coho salmon. 


\section{MATERIALS AND METHODS}

Bacterial isolate and preparation of LPS. The Vo isolate (\# 74-48) used in this study as the source of LPS and for challenging the juvenile coho was originally isolated from a farmed sockeye salmon Oncorhynchus nerka that had died of vibriosis (Evelyn \& Ketcheson 1980). The cells were grown for $32 \mathrm{~h}$ at $22^{\circ} \mathrm{C}$ in Brain Heart Infusion Broth (Difco, Detroit, MI, USA) supplemented with $1 \% \mathrm{NaCl}$. The cell wall LPS was extracted from the Vo cells by the method of Darveau \& Hancock (1983). LPS and LPS fractions were quantified by the chromogenic limulus amoebocyte lysate method (Whittaker Bio-Products, Walkersville, MD, USA).

Preparative SDS-Page and fractionation of LPS. Vo LPS (2.75 mg) was added to sample buffer and subjected to P-PAGE (Laemmli 1970) using a modified buffer system. For improved resolution of LPS in the gel, the sample buffer was modified to contain $4 \%$ SDS and $40 \mathrm{mM}$ ethylene diamine tetraacetic acid (EDTA) (Angus 1986). Both the $4.5 \%$ stacking gel and the $12.5 \%$ separating gel contained $0.1 \%$ SDS. The separating gel measured $140 \times 125 \times 3 \mathrm{~mm}$. The mixture of $275 \mu \mathrm{l}$ of the LPS solution and $2.75 \mathrm{ml}$ of sample buffer was boiled for $5 \mathrm{~min}$, cooled, and $275 \mu \mathrm{l}$ of the mixture was loaded per well. One additional lane was loaded with low molecular weight marker proteins (Bio-Rad Laboratories, Richmond, CA, USA). Electrophoresis was carried out for $9 \mathrm{~h}$ at a constant current of $30 \mathrm{~mA}$. Immediately after electrophoresis, the low molecular weight lane was excised, the marker proteins in the gel stained with Coomassie Blue, and the unreacted stain in the gel removed using an electrophoretic destainer (Pharmacia Fine Chemicals, Uppsala, Sweden). Based on the molecular weights of the protein markers, and on the position of the silverstained LPS bands (see below) detectable on a gel from a preliminary run, the LPS portion of the gel was cut into horizontal sections (fractions) corresponding to the following molecular weights: (1) 7 to $10 \mathrm{kD}$, (2) 10 to 15 $\mathrm{kD}$, (3) 15 to $20 \mathrm{kD}$, (4) 20 to $25 \mathrm{kD}$, (5) 25 to $35 \mathrm{kD}$, and (6) 40 to $50 \mathrm{kD}$. A second preparative gel was run as a control. One lane of this gel was loaded with the low molecular weight marker proteins and the remaining lanes were loaded with a mixture of pyrogen-free water (PFW) $(275 \mu \mathrm{l})$ and sample buffer $(2.75 \mathrm{ml})$. Following electrophoresis (as above), a $3 \mathrm{~cm}$ wide horizontal strip was removed from the middle of the gel. All of the excised gel sections were freeze-dried overnight and then ground separately in a clean mortar and pestle in the presence of liquid nitrogen. Each ground gel sample was then suspended in extraction buffer $10.01 \% \mathrm{SDS}$ and $50 \mathrm{mM} \mathrm{Na}_{4}$ EDTA in $10 \mathrm{mM}$ Tris base buffer, $\mathrm{pH} 8.0$ ) and extracted in a shaking water bath for $3 \mathrm{~h}$ at $60^{\circ} \mathrm{C}$. The gel particles were pelleted by centrifugation and the supernatants were collected. The pelleted gel was re-extracted in the same manner and the homologous supernatants were combined and then passed through glass wool filters (treated with dimethyldichlorosilane, Sigma Chemical Co., St. Louis, MO, USA) to remove any gel particles present. The LPS present in each of the fraction supernatants was then precipitated with 3 volumes of $0.375 \mathrm{M} \mathrm{MgCl}_{2}$ in $95 \%$ ethanol using the procedure described for extracellular LPS by Velji et al. (1990). Each of the LPS fractions was then run on an analytical SDS gel (dimensions: $140 \times$ $125 \times 1.5 \mathrm{~mm}$ ) for $14.5 \mathrm{~h}$ at a constant current of $20 \mathrm{~mA}$. Resulting LPS bands in the gels were visualized using the silver staining procedure of Tsai \& Frasch (1982) as modified by Hitchcock \& Brown (1983).

Experimental fish. The juvenile coho salmon used in the experiment were from an east coast of Vancouver Island (Canada) stock (Big Qualicum River) and had been reared in well water at the Department of Fisheries and Oceans Rosewall Creek facility. The fish were transported to our laboratory at the Pacific Biological Station and held in an $800 \mathrm{l}$ tank supplied with flowing dechlorinated city water. They were allowed to slowly acclimatize to a temperature of $13 \pm 1{ }^{\circ} \mathrm{C}$ before the experiment was carried out.

Vaccination and challenge procedures. The native LPS and the LPS in 5 of the 6 LPS fractions (Fractions 1 to 5) obtained by P-PAGE were dissolved in PFW to a concentration of $100 \mathrm{ng} \mathrm{ml}^{-1}$. Fraction 6 was not tested because in several trials it appeared to resist extraction from the gel using the extraction procedure just outlined. Each coho was injected intraperitoneally (IP) with $0.1 \mathrm{ml}$ of one or other of the LPS preparations $(10$ ng LPS per fish). Fish in the control groups were injected IP with $0.1 \mathrm{ml}$ of one or other of the following: PFW, an Escherichia coli 055:B5 (210-SE) LPS preparation (10 ng per fish) (Whittaker Bio-Products, Walkersville, MD, USA) or an extract of the control gel on which PFW had been run instead of the Vo LPS. Two lots of 20 coho each were used for each treatment and control group, the only exception to this being the groups treated with the E. coll LPS, where, because of a shortage of LPS, each replicate consisted of 12 fish. The various lots of fish were held in separate $35 \mathrm{I}$ tanks, each of which was supplied with dechlorinated city water at $13 \pm 1^{\circ} \mathrm{C}$. The fish were held for $21 \mathrm{~d}$ and then challenged IP with $0.1 \mathrm{ml}$ of live, saline-washed, log phase Vo cells $\left(1.7 \times 10^{5}\right.$ cells per fish). They were then observed for $14 \mathrm{~d}$, by which time deaths resulting from the challenge had ceased to occur. Kidney samples from $10 \%$ of the fish that died following the challenge were cultured on Tryptic Soy Agar (Difco, Detroit, MI, USA) supplemented with $1 \% \mathrm{NaCl}$ to verify that $\mathrm{VO}_{0}$ was the cause of death. Identification of Vo growth on the plates was accomplished serologically (agglutina- 
tion test) using a Vo-specific rabbit serum (Gibco, New York, NY, USA).

Statistical analysis. The $G$-test (log-likelihood ratio test) (Sokal \& Rohlf 1981) was used to determine if there were significant differences in deaths between replicates. If the differences were not significant $(p>0.05)$, the deaths in the replicates were combined and deaths in the various treatment groups were then compared with those in the control groups. Yate correction was applied because of the small sample sizes used.

\section{RESULTS AND DISCUSSION}

The silver-stained profile of native cell wall Vo LPS obtained by analytical SDS-PAGE (Fig. 1, Lane 7) was similar to that obtained by Chart \& Trust (1984) for Vo LPS. The profile consisted of a ladderlike pattern of bands reminiscent of those that occur with LPS from various members of the Enterobacteriaceae, and the various bands probably represented LPS molecules that differed from one another largely in the number of the O-polysaccharide repeat units present (Goldman \& Lieve 1980, Palva \& Makela 1980, Peterson \& McGroarty 1985). However, as our results indicate, the bands or fractions tended to give rise to additional faster-migrating LPS bands when subjected to re-electrophoresis. The additional bands migrated in a similar manner to bands yielded by native LPS, and the high- est molecular weight species detected in a given fraction always corresponded closely in its migration to that of the fraction from which it was derived (Fig. 1, Lanes 1 to 5). It appears, therefore, that aggregation of the various Vo LPS molecular species occurs, a phenomenon that has also been reported for LPS from a number of other Gram negative bacteria (Hurlbert \& Hurlbert 1977, Logan \& Trust 1984, Ohta et al, 1985) and that is favoured (and becomes evident) when heavily loaded gels are used. Native LPS isolated from certain bacteria may therefore consist of more than one molecular species, and the various molecular species can occur as aggregates. Hurlbert \& Hurlbert (1977) found that the LPS fractions (aggregates) from P-PAGE were moderately stable: they migrated on re-electrophoresis to their original positions, showing no disaggregation, as long as electrophoresis occurred in a non-disaggregating system (i.e. one lacking SDS).

Protection against challenge with Vo was LPSspecific because it was obtained only when LPS derived from Vo was used in the vaccines (Table 1). Further, when the various Vo LPS fractions from the P-PAGE were compared for their protective properties in coho salmon, there appeared to be a relationship between the strength of the protection conferred and the apparent molecular weight of the LPS in the fraction (Table 1). The RPS declined from 51.4 to $5.9 \%$ as the molecular weight of the slowest migrating LPS components in the fractions decreased. On statistical analysis, however,
Fig. 1 Silver-stained lipopolysaccharide (LPS) patterns obtained on an analytical gel by sodium dodecyl sulphate - polyacrylamide gel electrophoresis (SDS-PAGE) using samples representing native Vibrio or dalii LPS (Lane 7) and various fractions of decreasing mobility (Lanes 1 to 6 ) obtained from Vo LPS using a preparative gel and SDS-PAGE. Note: The slowest migrating LPS fraction consistently appeared to resist elution from the preparative gel (see, however, 'Results and discussion') and thus it always failed to show up on analytical gels (Lane 6). The migration distances of various proteins of known molecular weights (in kilodaltons) are indicated by the horizontal lines on the left

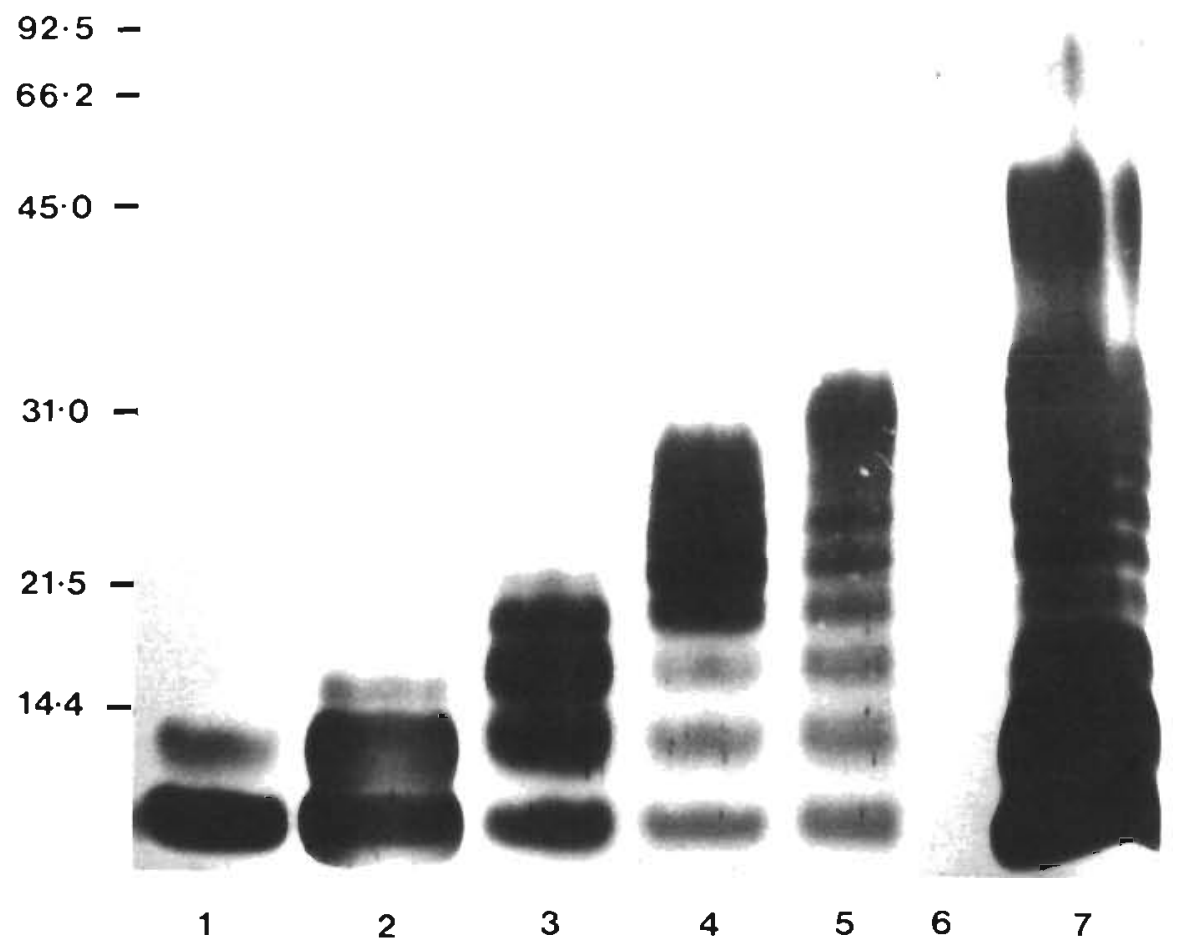


Table 1. Oncorhynchus kisutch. Mortalities following challenge with Vibrio ordalii (Vo) cells of juvenile coho salmon vaccinated with various Vo and Escherichia coli lipopolysaccharide (LPS) preparations and with various placebos. Experiment was carried out in fresh water at $13 \pm 1{ }^{\circ} \mathrm{C}$ with fish averaging $14.1 \pm 4.5 \mathrm{~g}$; fish were challenged intraperitoneally with $1.7 \times 10^{5}$ viable Vo cells $21 \mathrm{~d}$ post vaccination; mortalities were monitored for $14 \mathrm{~d}$ post challenge

\begin{tabular}{|c|c|c|c|c|c|c|}
\hline $\begin{array}{l}\text { Type of } \\
\text { preparation } \\
\text { injected }\end{array}$ & $\begin{array}{l}\text { Fraction no. } \\
\text { (approximate size } \\
\text { of LPS, kD) }\end{array}$ & $\begin{array}{c}\text { Dose of } \\
\text { LPS }\end{array}$ & $\begin{array}{l}\text { No. dead }{ }^{1} \\
\operatorname{tank}{ }^{1} \\
\left(t_{1} / t_{2}\right)\end{array}$ & $\begin{array}{c}\text { Total no. } \\
\text { dead/no. } \\
\text { challenged }^{2}\end{array}$ & $\begin{array}{l}\text { Total } \% \\
\text { mortality }\end{array}$ & $\begin{array}{c}\mathrm{RPS}^{3} \\
(\%)\end{array}$ \\
\hline $\mathrm{PFW}^{4}$ & - & - & $15 / 19$ & $34 / 40^{\circ}$ & 85.0 & 0 \\
\hline Blank gel extract & 0 & - & $18 / 17$ & $35 / 40^{d}$ & 87.5 & - \\
\hline \multirow[t]{6}{*}{ Vibrio ordalii } & N-LPS 5 & $10 \mathrm{ng}$ & $1 / 4$ & $5 / 40^{\mathrm{b}}$ & 12.5 & 85.3 \\
\hline & $\begin{array}{c}5 \\
(<35.0)\end{array}$ & $10 \mathrm{ng}$ & $12 / 5$ & $17 / 40^{c}$ & 42.5 & 51.4 \\
\hline & $\begin{array}{c}4 \\
(<31.0)\end{array}$ & $10 \mathrm{ng}$ & $11 / 11$ & $20 / 40^{d}$ & 55.0 & 35.3 \\
\hline & $\begin{array}{c}3 \\
(<22.0)\end{array}$ & $10 \mathrm{ng}$ & $16 / 12$ & $28 / 40^{\circ}$ & 70.0 & 17.6 \\
\hline & $\begin{array}{c}2 \\
(<17.0)\end{array}$ & $10 \mathrm{ng}$ & $15 / 17$ & $32 / 40^{a}$ & 80.0 & 5.9 \\
\hline & $\begin{array}{c}1 \\
(<14.4)\end{array}$ & $10 \mathrm{ng}$ & $12 / 20$ & $32 / 40$ & 80.0 & 5.9 \\
\hline Escherichia coli & N-LPS & $10 \mathrm{ng}$ & $11 / 10$ & $21 / 24$ & 95.8 & - \\
\hline \multicolumn{7}{|c|}{$\begin{array}{l}{ }^{1} \text { Comparison of mortalities between replicate tanks of each treatment was shown to be non-significant }(p>0.05) \text { excep } \\
\text { Fraction } 1(p<0.05) \\
{ }^{2} \text { Combined mortalities of each treatment followed by different letters are significantly different at } \mathrm{p}<0.05 \text { from controls } \\
{ }^{3} \text { Calculated as per Amend }(1981): \text { RPS }=\left[1-\left({ }^{0}, \text { vaccinate mortality } / \% \text { PFW control mortality }\right)\right] \times 100 \% \\
{ }^{4} \text { PFW: Pyrogen-free water } \\
{ }^{5} \text { N-LPS: Native unfractionated LPS }\end{array}$} \\
\hline
\end{tabular}

only 2 fractions (Fractions 4 and 5) yielded significant protection $(p<0.05)$ : those containing LPS of the highest molecular weight $(20$ to $35 \mathrm{kD})$. These findings indicate that the size of the O-polysaccharide component of the LPS molecule, which is dependent on the number of $\mathrm{O}$-polysaccharide repeat units present, is an important factor determining immunogenicity. The basis for this conclusion is that the coho injected with the various fractions each received a constant amount of lipid A [lipid A is the LPS component actually measured by the LPS assay technique used in our study (Tanamato et al. 1984)]. Variations in the strength of the protection elicited could thus not have been related to the lipid $A$ portion of the LPS molecules.

Unfortunately, the immunogenicity of LPS in Fraction 6 was not tested because, in 3 attempts, we appeared unable to remove it from the preparative gel using the extraction procedures outlined earlier. In fact, however, subsequent tests indicated that our problem with this fraction was due to its occurrence in low concentration relative to that of the other Vo LPS fractions. (It was the first fraction to disappear when increasingly dilute Vo LPS preparations were electrophoresed; data not shown). Thus, when re-electrophoresed following extraction, its separated subcomponents yielded bands that were too weak to be seen. The net outcome is that we do not know the extent to which this fraction contri- buted to the superior protection obtained with native LPS relative to that obtained with Fractions 4 and 5 . Superior protection observed with native LPS may also have been partly a function of aggregation of the various LPS molecules produced by Vo. Our data indicate that aggregation of the various molecular species occurred, and aggregation would be expected to result in a complex that was larger, more persistent in fish, and thus more immunogenic than the individual LPS fractions. Aggregation may thus be another factor contributing to the immunogenicity of LPS preparations. It should be pointed out, however, that aggregation per se was obviously not sufficient to ensure immunogenicity of all of the LPS molecules. When, for example, the fastest migrating LPS fractions (Fractions 1 and 2), presumably representing the smallest LPS molecules, were injected into the coho under conditions that would have favoured aggregation (i.e. in the presence of $\mathrm{Mg}^{++}$and absence of SDS or of EDTA), there was no evidence of protection (Table 1).

In summary, native Vo LPS appears to be comprised of a number of different-sized LPS molecules, the higher molecular weight species apparently being the dominant immunogenic components. Experiments are underway to determine whether the immunogenic components are the only ones recognized by the immune system of the coho. 
Acknowledgements. We thank J. E. Ketcheson and L. Prosperi-Porta for their excellent technical assistance, Dr $\mathrm{T}$ Beacham for his advice on the statistical analyses, and Dr R. E W. Hancock, Department of Microbiology, University of British Columbia, for his critical reading of the manuscript. This research was partially funded by an operating grant to L.J.A from the National Science and Engineering Research Council of Canada.

\section{LITERATURE CITED}

Amend, D. F. (1981). Potency testing of fish vaccines. Develop. biol. Standard. 49: 447-454

Angus, B. L. (1986). Structural and functional studies on the role of the outer membrane of Pseudomonas aeruginosa in resistance and permeability to antibiotics. Ph.D. thesis University of British Columbia, Vancouver

Chart, H., Trust, T. J. (1984). Characterization of the surface antigens of the marine fish pathogens Vibrio anguillarum and Vibrio ordalii. Can. J. Microbiol, 30: 703-710

Darveau, R. P., Hancock, R. E. W. (1983). Procedure for isolation of bacterial lipopolysaccharides from both smooth and rough Pseudomonas aeruginosa and Salmonella typhimurium strains. J. Bacteriol. 155: 831-838

Evelyn, T P. T (1984). Immunization against pathogenic vibrios. In: de Kinkelin, P., Michel, C. (eds.) Symposium on fish vaccination. Off. Intl. des Epizoot., Paris, p. 121-150

Evelyn, T P. T. (1988). Vibrio vaccines for salmonids. In Congress Proceedings, Aquaculture International Congress and Exposition. Aquacult. Intl Congress, B.C. Corp., Vancouver, B.C., Canada, p. 459-469

Evelyn, T. P. T., Ketcheson, J. E. (1980). Laboratory and field observations on antivibriosis vaccines. In: Ahne, W. (ed.) Fish diseases, Third COPRAQ Session. Springer-Verlag, Berlin, Heidelberg, New York, p. 45-52

Goldman, R., Lieve, L. (1980). Heterogeneity of antigenicside-chain length in lipopolysaccharide from Escherichia coli 0111 and Salmonella typhimurium LT2. Eur. J. Biochem. 107: 145-153

Hitchcock, P. J., Brown, T M. (1983). Morphological

Editional responsibility: Managing Editor heterogeneity among salmonella lipopolysaccharide chemotypes in silver-stained polyacrylamide gels. J. Bacteriol. 154: 269-277

Hurlbert, R. E., Hurlbert, I. M. (1977). Biological and physicochemical properties of the lipopolysaccharide of Chromatium vinosum. Infect. Immun. 16: 983-994

Ohta, M., Rothmann, J., Kovats, E., Pham, P. H., Nowotny, A. (1985). Biological activities of lipopolysaccharide fractionated by preparative acrylamide gel electrophoresis. Microbiol. Immunol. 29: 1-12

Laemmli, U. K. (1970). Cleavage of structural proteins during the assembly of head bacteriophage T4. Nature, Lond. 227: $680-685$

Logan, S., Trust, T J. (1984). Structural and antigenic heterogeneity of lipopolysaccharides of Campylobacter jejuni and Campylobacter coli. Infect. Immun. 45: 210-216

Palva, T., Makela, P. H. (1980). Lipopolysaccharide heterogeneity in Salmonella typhimurium analyzed by sodium dodecyl sulphate/polyacrylamide gel electrophoresis. Eur J. Biochem. 107: 137-143

Peterson, A. L., McGroarty, E. J. (1985). High-molecularweight components in lipopolysaccharides of Salmonella typhimurium, Salmonella minnesota, and Escherichia coli. J. Bacteriol. 162: 738-745

Sokal, R. S., Rohlf, F. J. (1981). Biometry. The principles and practice of statistics in biological research, 2 nd edn. W. H Freeman and Co., New York

Tanamomto, K., Zchinger, U., McKenzie, G. R, Galanos, C. Rietschel, E. T., Luderitz, O., Kusumoto, S., Shiba, T (1984). Biological activities of synthetic lipid A analogs: pyrogenicity, lethal toxicity, anti-complement activity and induction of gelation of limulus amoebocyte lysate. Infect. Immun. 44: 421-426

Tsai, C.-M., Frasch, C. E. (1982). A sensitive silver stain for detecting lipopolysaccharide in acrylamide gels. Analyt Biochem. 119: 115-119

Velji, M. J., Albright, L. J., Evelyn, T. P. T. (1990). Protective immunity in juvenile coho salmon (Oncorhynchus kisutch) following immunization with Vibrio ordalii lipoplysaccharide or from exposure to live $V$. ordalii cells. Dis. aquat. Org. 9: 25-29

Manuscript first received: June 13, 1991

Revised version accepted: October 9, 1991 